\title{
Haemoglobin and ferritin concentrations in men and women: cross sectional study
}

\author{
Jill Waalen, Vincent Felitti, Ernest Beutler
}

Rushton et al found that of all the primates, only in humans do females have lower blood haemoglobin concentrations than males. ${ }^{1}$ The usual explanation, of the effect of androgens on erythropoiesis, does not explain the difference between species. ${ }^{2}$ The explanation of Rushton et al of iron deficiency among females, does not withstand scrutiny. ${ }^{1}$

\section{Participants, methods, and results}

We are engaged in a large scale study of iron storage disease in patients attending a health appraisal centre at Kaiser Permanente, San Diego. Approximately 500000 people, a third of the population of San Diego's metropolitan area, are members of this medical care programme. Patients with Medicare or in an employee group can join. In any four year period, $81 \%$ of members over the age of 26 attend the centre. Most members are in good health. ${ }^{3}$ These patients are an ideal group on which to test the proposal that the difference in haemoglobin values of men and women is largely due to iron deficiency, because we have obtained transferrin saturation and serum ferritin concentrations from all of the patients. So far 26614 white participants aged 26 to 99 years have been screened.

We used a comprehensive questionnaire and medical records to exclude patients who have diseases that might influence the haemoglobin concentration in the blood. Rheumatoid arthritis (1048 patients) and chronic renal failure (seven patients) were considered to have the greatest chronic effect on the normal ironhaemoglobin relationship. No other exclusions were made.

Of the remaining 25559 participants, 12731 were men and 12828 were women. Part a of the figure shows that mean haemoglobin concentrations are greater in men than in women at any given age. Parts b and $\mathrm{c}$ of the figure show an approximate $10 \mathrm{~g} / \mathrm{l}$ difference in mean haemoglobin concentrations between men and women aged 26 to 55 years at any given transferrin saturation or serum ferritin concentration. This apparent difference in haemoglobin concentration between the sexes, therefore, is not because of iron deficiency. Neither do our data support the suggestion that this sex difference vanishes with age: part $d$ of the figure shows a difference of about $10 \mathrm{~g} / \mathrm{l}$ exists at each transferrin saturation concentration between men and postmenopausal women older than 55 years.

\section{Comment}

The evidence does not support the idea that the lower haemoglobin concentrations in women are due to iron deficiency. We agree that iron deficiency is an important health problem, and we have repeatedly made this point over more than 40 years. ${ }^{4}$

In claiming that humans are the only menstruating primates to have sex differences in haemoglobin values, Rushton et al overlooked a study establishing
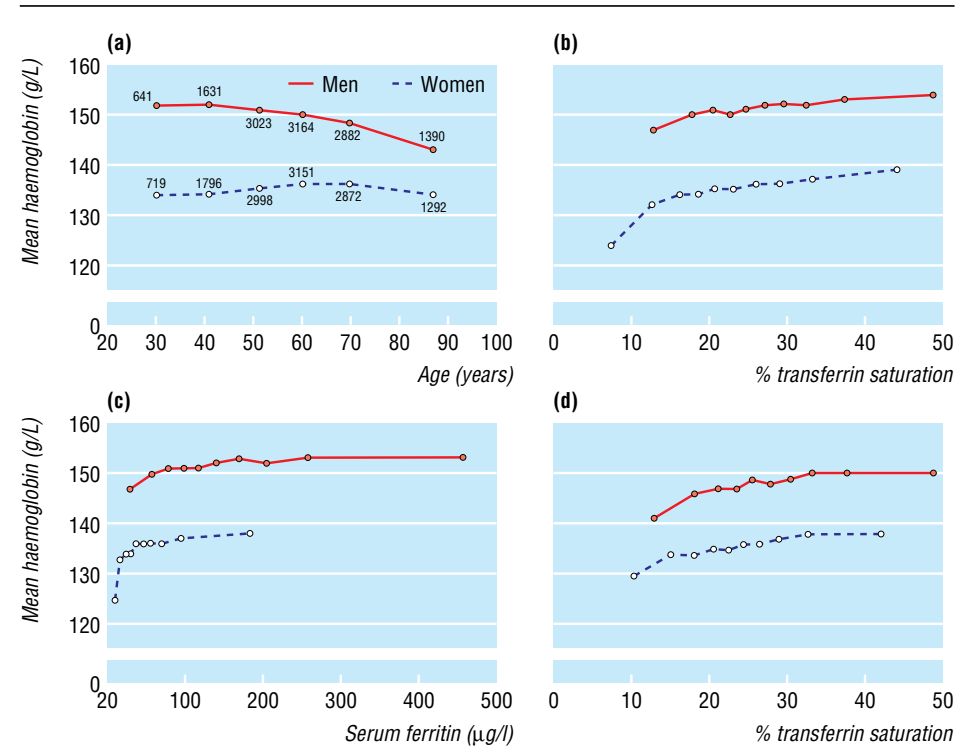

Mean concentration of haemoglobin in healthy white participants as a function of: (a) age, stratified as $26-35,36-45,46-55,56-65,66-75$, and 76-99 years, plotted at the interval midpoint, number of participants shown; $(b)$ per cent transferrin saturation in 26-55 year olds; (c) serum ferritin concentration in 26-55 year olds; and (d) per cent transferrin saturation in $>55$ year olds, divided into tenths and plotted at the mean for each tenth. Error bars show the standard error in the mean. Group sizes are given on bmj.com

reference ranges for haemoglobin in cynomolgus macaques. ${ }^{5}$ In that study, a statistically significant difference of approximately $10 \mathrm{~g} / 1$ in mean haemoglobin concentrations was found between male macaques $(120 \mathrm{~g} / \mathrm{l})$ and female macaques $(110 \mathrm{~g} / \mathrm{l})$ despite similar mean ferritin values between the sexes. ${ }^{5}$

This is manuscript number 14266-MEM from The Scripps Research Institute.

Contributors: VF directed the collection of the clinical data. EB planned and organised the Scripps-Kaiser Hemochromatosis Study and oversees analyses of all data from the study. JW analysed the data. The paper was written by JW and EB.

Funding: Supported by grants DK53505-04, DK 07022-20, and RR00833 from the NIH and supplemented with a grant from the Division of Nutrition and Physical Activity, Centers for

Disease Control and Prevention, and funds from the Stein Endowment Fund.

Competing interests: None declared.

1 Rushton DH, Dover R, Sainsbury AW, Norris MJ, Gilkes JJH, Ramsay ID. Why should women have lower reference limits for haemoglobin and ferritin concentrations than men? BMJ 2001;322:1355-7.

2 Gardner FH, Nathan DG, Piomelli S, Cummins JF. The erythrocythaemic effects of androgen. Br J Haematol 1968;14:611-5.

3 Beutler E, Felitti VJ, Koziol JA, Ho NJ, Gelbart T. Low penetrance of the $845 \mathrm{G} \rightarrow \mathrm{A}(\mathrm{C} 282 \mathrm{Y})$ HFE hereditary haemochromatosis mutation in the United States. Lancet 2002;359:211-8.

4 Beutler E, Larsh SE, Gurney CW. Iron therapy in chronically fatigued, non-anemic women: a double-blind study. Ann Intern Med 1960;52: 378-94.

5 Giulietti M, La Torre R, Pace M, Iale E, Patella A, Turillazzi P. Reference blood values of iron metabolism in cynomolgus macaques. Lab Anim Sci 1991;41:606-8.

(Accepted 28 December 2001)
Department of

Molecular and Experimental Medicine, The Scripps Research Institute, La Jolla, CA 92037, USA Jill Waalen research fellow Ernest Beutler chairman

Kaiser Permanente, Department of

Preventive

Medicine,

San Diego,

CA 92111

Vincent Felitti director

Correspondence to: J Waalen

jwaalen@scripps.edu

BMJ 2002;325:137

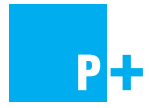

Group sizes are on bmj.com 